\title{
PHASE TRANSFORMATIONS AND THERMAL CONDUCTIVITY OF THE In-Ag ALLOYS
}

\author{
Dragan Manasijević ${ }^{1 *}$ Ljubiša Balanović ${ }^{1}$, Ivana Marković ${ }^{1}$, Milan Gorgievski ${ }^{1}$, \\ Uroš Stamenković ${ }^{1}$, Duško Minić ${ }^{2}$, Milena Premović ${ }^{2}$, Nada Štrbac ${ }^{l}$ \\ ${ }^{1}$ University of Belgrade, Technical Faculty in Bor, Bor, Serbia \\ ${ }^{2}$ University of Priština, Faculty of Technical Sciences, Kosovska Mitrovica, Serbia
}

Received 05.04.2020

Accepted 09.06.2020

\begin{abstract}
Phase transformations and thermal conductivity of three In-Ag alloys with 5, 15, and $45 \mathrm{wt} . \%$ of $\mathrm{Ag}$ were experimentally investigated in the present work. Phase transition temperatures were measured using differential scanning calorimetry (DSC). DSC heating scans were compared with the equilibrium and non-equilibrium solidification paths, calculated by using optimized thermodynamic parameters from literature and calculation of phase diagrams (CALPHAD) method. The flash method was employed for the determination of thermal diffusivity and thermal conductivity of the investigated alloys in the temperature range from 25 to $100{ }^{\circ} \mathrm{C}$. It has been found that an increase in silver content does not lead to an increase in the thermal conductivity of the investigated alloys. Thermal conductivities for all three investigated In-Ag alloys slightly decrease with temperature increasing.
\end{abstract}

Keywords: In-Ag system; DSC; solidification; thermal conductivity.

\section{Introduction}

Indium is a low-melting, highly malleable and ductile metal. It is often used as a strengthening agent in lead-based solder and as a base material in low-meltingtemperature solders [1]. Other applications of indium include nuclear reactor control rods, sodium lamps, semiconductors, solar cells [1]. Silver is one of the most frequently used alloying elements in indium-based solders. Silver has superior electrical and thermal conductivity, excellent oxidation and corrosion resistance and good mechanical properties. Silver and its alloys have found broad use in electronic industries, photography, brazing, medicine, bearings, and electrical contacts [2].

${ }^{*}$ Corresponding author: Dragan Manasijević,_dmanasijevic@tfbor.bg.ac.rs 
The phase diagram of the Ag-In system is fairly complex. Moser et al. [3] presented a literature review of previously published investigations related to the thermodynamics and phase equilibria in the Ag-In system. They also investigated the phase diagram of the Ag-In system using differential scanning calorimetry and metallographic techniques and performed thermodynamic modeling of this system. The optimized phase diagram of the Ag-In system, constructed using thermodynamic parameters from the COST 531 lead-free solders thermodynamic database [4], is presented in Fig. 1.

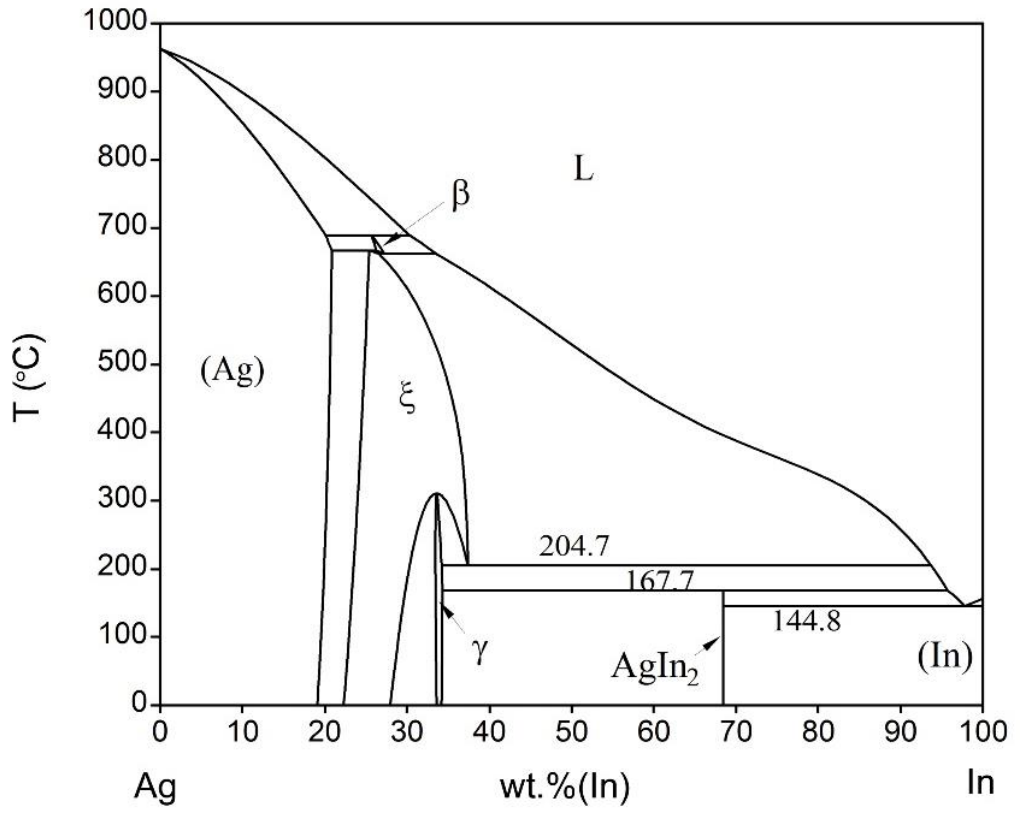

Fig. 1. The phase diagram of the Ag-In system [4].

In the In-rich part of the phase diagram, three invariant reactions appear. The Inbased In-Ag alloys start to crystallize by reaching the liquidus temperatures with the formation of the primary $\xi$ phase from the melt. At $204.7^{\circ} \mathrm{C}$ metatectic reaction appears which causes decomposition of $\xi$ phase to the $\gamma$ and liquid phases according to $\xi \rightarrow \gamma$ +liquid reaction. With further cooling, at $167.7^{\circ} \mathrm{C}$ peritectic reaction $\gamma+$ liquid $\rightarrow \mathrm{AgIn}_{2}$ occurs, resulting in the formation of the $\mathrm{AgIn}_{2}$ phase. Finally, for the alloys with In concentration higher than 66.7 at.\%, solidification ends with the appearance of liquid $\rightarrow \mathrm{AgIn}_{2}+(\mathrm{In})$ eutectic reaction at $144.8{ }^{\circ} \mathrm{C}$.

The thermal properties of the In-Ag alloys have been rarely investigated. Moser et al. [3] measured surface tension and density of liquid Ag-In alloys. Kondo et al. [5] investigated thermal conductivity and electrical resistivity of liquid Ag-In alloys. They have found that thermal conductivity of liquid Ag-In alloys is much lower than that of pure liquid $\mathrm{Ag}(177 \mathrm{~W} / \mathrm{mK}$ at $1273 \mathrm{~K})$, but almost the same or less than that of liquid In $(59.2 \mathrm{~W} / \mathrm{mK}$ at $1273 \mathrm{~K})$ in all $\mathrm{Ag} 1-\mathrm{xInx}(\mathrm{x}=0.2-0.8)$ alloys at investigated temperatures. Thermal property data for several commercial In-Ag solder alloys (In-3\% Ag and In$10 \% \mathrm{Ag}$ alloys) can be found in the reference literature [1]. 
As a contribution to a better understanding of properties of the In-Ag alloys in this study phase transformations and thermal conductivity of several In-rich In-Ag alloys were investigated. The In-Ag alloys with 5, 15, and 45 wt.\% of Ag were prepared and characterized using several experimental techniques. Conducted investigations include the determination of phase transition temperatures using the DSC method and thermal conductivity measurements using the xenon-flash technique.

\section{Experimental}

Three In-Ag alloys were prepared by mixing and melting weighted pieces of pure In (99.999\%, Alfa Aesar) and Ag (99.99\%, Alfa Aesar) in evacuated quartz tubes. Samples were heated at $1000{ }^{\circ} \mathrm{C}$ for $30 \mathrm{~min}$. The melts were stirred by shaking the quartz tubes several times to ensure the homogenization of the molten alloys and slowly cooled inside the furnace. The total masses of the prepared samples were about $4 \mathrm{~g}$. The total mass losses of prepared samples were less than 1 mass $\%$, so the nominal compositions of the alloys were accepted for further analysis.

Phase transformations and their heat effects were investigated by using simultaneous thermal analyzer SDT Q600 (TA Instruments).

Experimental parameters were: sample's mass $50 \mathrm{mg}$, heating rate $5{ }^{\circ} \mathrm{Cmin}^{-1}$, empty alumina crucible as reference material. The DSC instrument was calibrated measuring the melting points and the heat of melting of a known mass of standard materials (pure metals: Ag, In, and Zn).

Thermal diffusivity and specific heat capacity were measured on the Discovery Xenon Flash (DXF-500) instrument over a range of temperatures from 25 to $100{ }^{\circ} \mathrm{C}$. The cast In-Ag samples were shaped into round disks $(12.6 \mathrm{~mm}$ in diameter and $2 \mathrm{~mm}$ thick with plane-parallel ground end faces) using hydraulic pressing and aged at $80{ }^{\circ} \mathrm{C}$ to relieve internal stresses created during plastic deformation. Samples were placed in a vacuum furnace and heated at a constant rate of $10{ }^{\circ} \mathrm{Cmin}^{-1}$ to a measurement temperature. When the furnace temperature was sufficiently stable (temperature changes of less than $1^{\circ}$ for $60 \mathrm{~s}$ ) the front surface of the specimen was heated by an energy pulse from the xenon-lamp. Temperatures of the rear face of the samples were monitored using the nitrogen-cooled IR detector [6].

\section{Results and discussion}

\section{Investigation of melting behavior}

Experimentally obtained results were compared with the calculated equilibrium and non-equilibrium Scheil solidification paths using the optimized thermodynamic parameters from the COST 531 lead-free solder database [4] and PANDAT software [7]. Equilibrium solidification path corresponds to the phase diagram of the Ag-In system i.e. to the conditions of very (infinitely) slow cooling/heating of the alloy. Scheil model corresponds to the conditions of very fast cooling/heating of the alloy. The basic assumption of the Scheil model is that during cooling/heating diffusion in solid phases is not occurring and diffusion in the liquid phase is infinitely fast [8]. The onset temperature of the DSC peak was considered as the temperature of the invariant reaction, and the peak temperature of the last thermal effect on heating was selected as the liquidus temperature [8]. 
Fig. 2 shows the calculated equilibrium solidification path (Fig. 2a), nonequilibrium Scheil solidification path (Fig. 2b), and related DSC heating curve (Fig. 2c) for the investigated $\mathrm{In}-5 \% \mathrm{Ag}$ alloy.

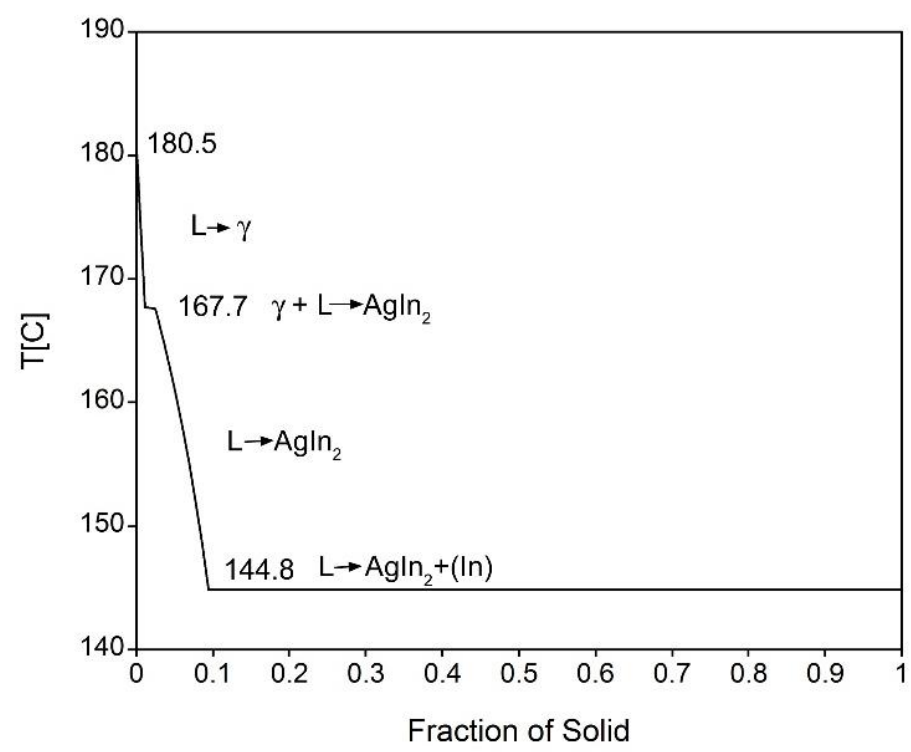

(a)

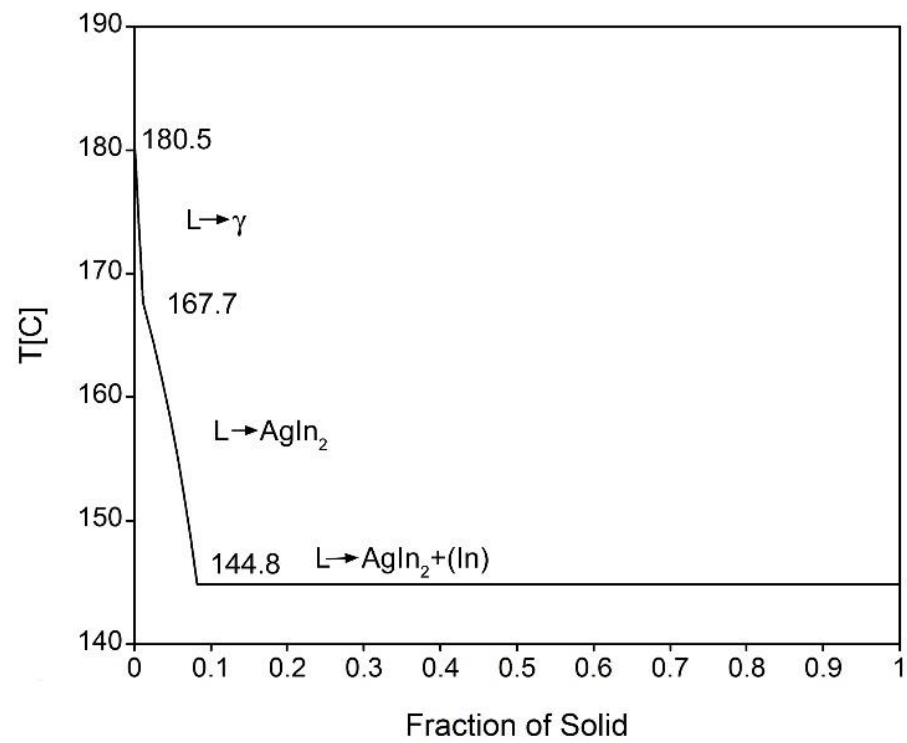

(b) 


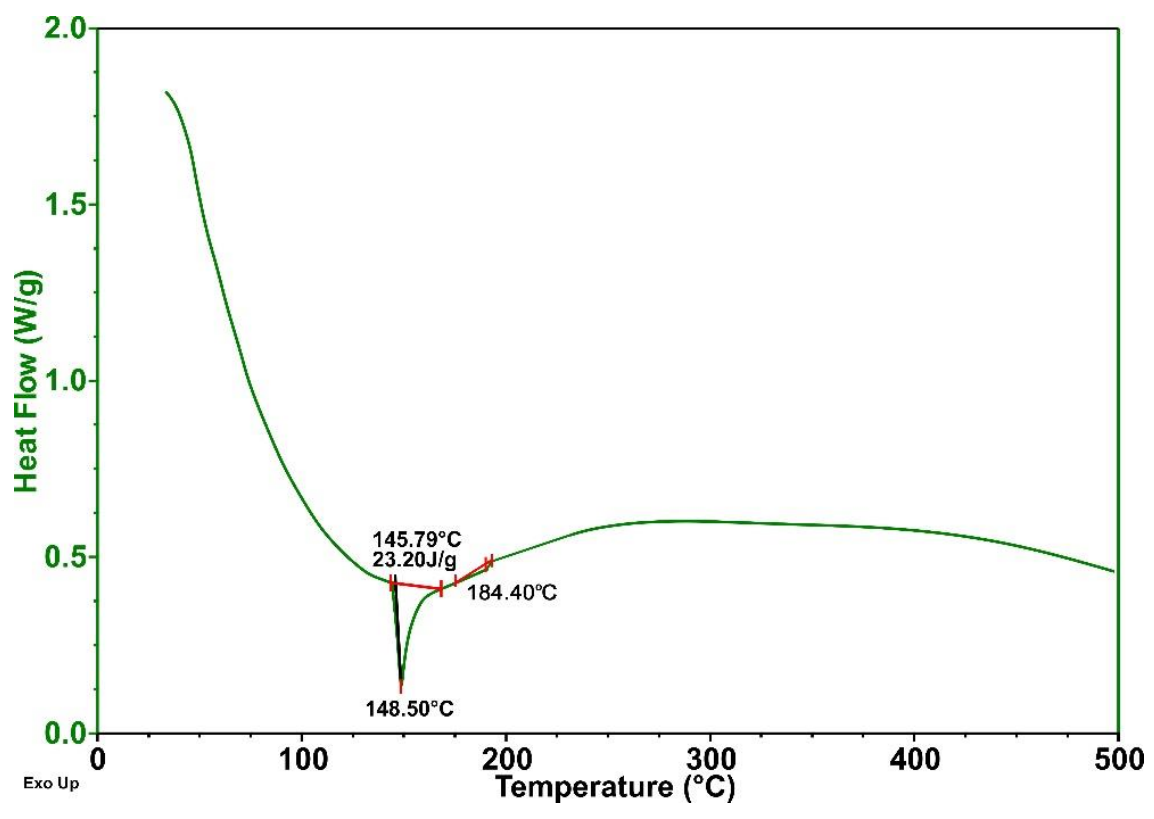

(c)

Fig. 2. In-5\%Ag alloy: (a) Equilibrium solidification path; (b) Non-equilibrium (Scheil) solidification path; (c) DSC heating curve.

Under the equilibrium assumption, the solidification sequence is: $L \rightarrow \gamma$, $\gamma+\mathrm{L} \rightarrow \mathrm{AgIn}_{2}$ (invariant), $\mathrm{L} \rightarrow \mathrm{AgIn}_{2}, \mathrm{~L} \rightarrow \mathrm{AgIn}_{2}+(\mathrm{In})$ (invariant). At the room temperature microstructure of the alloy consists of (In) solid solution ( $84 \%$ phase fraction) and AgIn 2 phase (16\% phase fraction). Under Scheil condition, the solidification sequence is: $\mathrm{L} \rightarrow \gamma$, $\mathrm{L} \rightarrow \mathrm{AgIn}_{2}, \mathrm{~L} \rightarrow \mathrm{AgIn}_{2}+(\mathrm{In})$ (invariant). It can be seen the Scheil solidification path does not include a peritectic $\gamma+$ liquid $\rightarrow \mathrm{AgIn}_{2}$ reaction and includes only eutectic liquid $\rightarrow \mathrm{AgIn}_{2}+(\mathrm{In})$ reaction. DSC heating curve exhibits one pronounced peak with onset temperature $145.8^{\circ} \mathrm{C}$ which is slightly higher than the calculated temperature of the liquid $\rightarrow \mathrm{AgIn}_{2}+(\mathrm{In})$ reaction $144.8^{\circ} \mathrm{C}$. The second detected a small peak at $184.4{ }^{\circ} \mathrm{C}$ is related to the alloy liquidus temperature.

Fig. 3 presents the calculated equilibrium solidification path (Fig. 3a), nonequilibrium solidification path (Fig. 3b), and DTA heating curve (Fig. 3c) for the investigated $\mathrm{In}-15 \% \mathrm{Ag}$ alloy. 


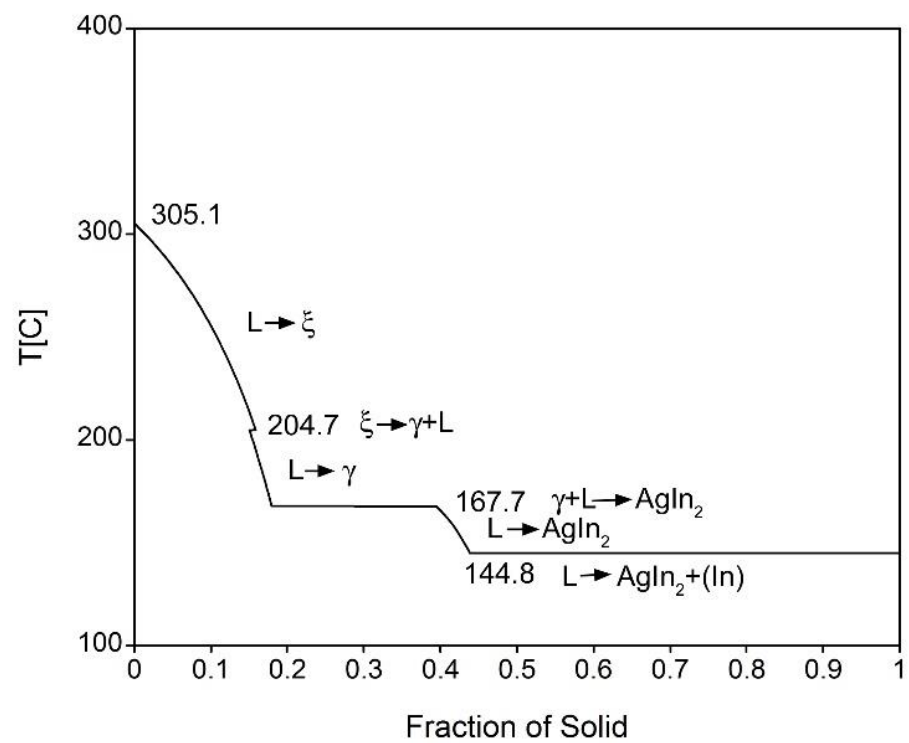

(a)

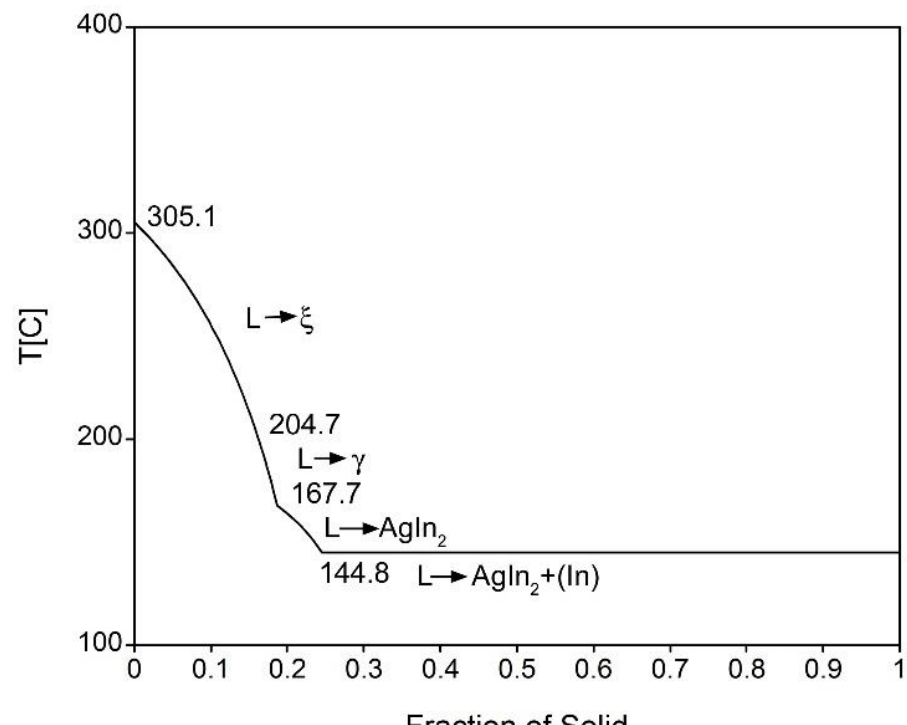

Fraction of Solid

(b) 


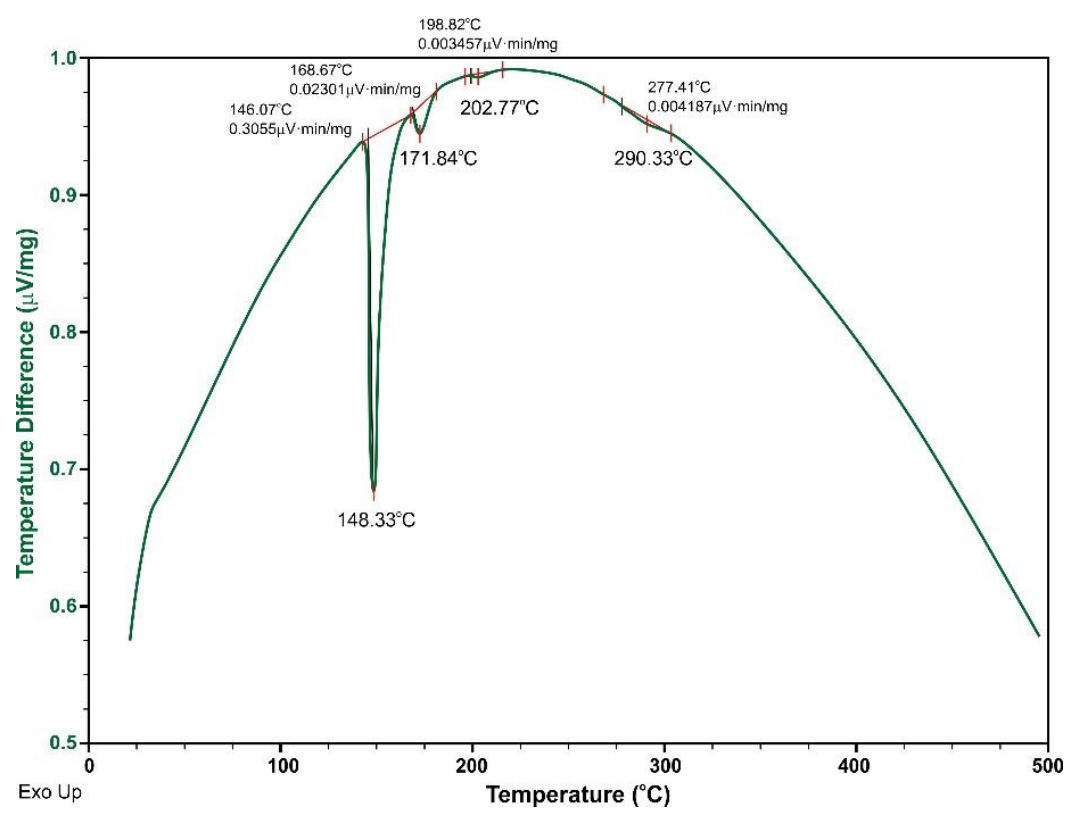

(c)

Fig. 3. In-15\%Ag alloy: (a) Equilibrium solidification path; (b) Non-equilibrium (Scheil) solidification path; (c) DTA heating curve.

The calculated equilibrium solidification path for the In-15Ag alloy (Fig.3a) includes three invariant reactions at $204.7,167.7$, and $144.8^{\circ} \mathrm{C}$. An invariant reaction at $204.7^{\circ} \mathrm{C}$ is metatectic $\xi \rightarrow \gamma$ +liquid reaction. The horizontal part of the solidification path at $167.7^{\circ} \mathrm{C}$ is related to the peritectic $\gamma+$ liquid $\rightarrow \mathrm{AgIn}_{2}$ reaction and the horizontal part of the solidification path at $144.8{ }^{\circ} \mathrm{C}$ represents eutectic liquid $\rightarrow \mathrm{AgIn}_{2}+(\mathrm{In})$ reaction. According to the results of calculation, solidification of the alloy starts at $305.1{ }^{\circ} \mathrm{C}$ with the formation of $\xi$ phase from the melt and finishes at $144.8^{\circ} \mathrm{C}$ with the occurrence of eutectic liquid $\rightarrow \mathrm{AgIn}_{2}+(\mathrm{In})$ reaction. At room temperature microstructure of the alloy consists of (In) solid solution (52\% phase fraction) and $\mathrm{AgIn}_{2}$ phase (48\% phase fraction). The calculated non-equilibrium solidification path according to the Scheil model is presented in Fig. 3b. It can be seen the Scheil solidification path does not include metatectic $\xi \rightarrow \gamma+$ liquid and peritectic $\gamma+$ liquid $\rightarrow \mathrm{AgIn}_{2}$ reactions and includes only eutectic liquid $\rightarrow \mathrm{AgIn}_{2}+(\mathrm{In})$ reaction. Although metatectic and peritectic reactions are quite similar to the eutectic reaction from the thermodynamic point of view, they are very different in their diffusion kinetics [9]. Both metatectic and peritectic reactions involve significant solute diffusion in solid phases at the reaction temperature, which is generally very slow comparing to the diffusion in the liquid phase. For the In-15\%Ag alloy, the primary measuring DTA signal (the temperature difference between the sample and reference in $\mu \mathrm{V}$ (thermal voltage)) (Fig. 3c) has shown better sensitivity than the DSC signal (heat-flux difference in $\mathrm{mW}$ ). Four phase transition temperatures for the In-15\% Ag alloy were identified and they are in reasonable agreement with the results of thermodynamic calculations. The onset temperature of the first and largest peak $\left(146.1{ }^{\circ} \mathrm{C}\right)$ is close to the calculated temperature of eutectic $\mathrm{AgIn}_{2}+(\mathrm{In}) \rightarrow$ liquid reaction 
$\left(144.8^{\circ} \mathrm{C}\right)$. The onset temperature of the second detected sharp peak $\left(168.7^{\circ} \mathrm{C}\right)$ is related to the peritectic $\mathrm{AgIn}_{2} \rightarrow \gamma+$ liquid reaction at the calculated temperature of $167.7{ }^{\circ} \mathrm{C}$. Third, a very small heat effect at $198.8^{\circ} \mathrm{C}$, corresponds to the metatectic $\gamma+$ liquid $\rightarrow \xi$ reaction. The fourth peak with a peak temperature of $290.3{ }^{\circ} \mathrm{C}$ is associated with the end of the melting process.

Calculated equilibrium solidification path, non-equilibrium solidification path, and DSC heating curve for the investigated In-45\% Ag alloy are shown in Fig. 4.

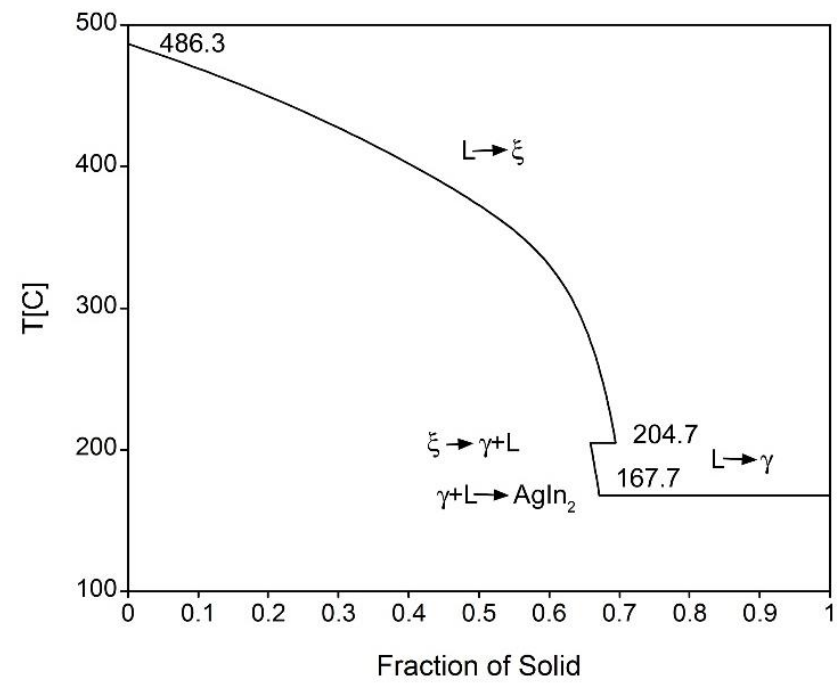

(a)

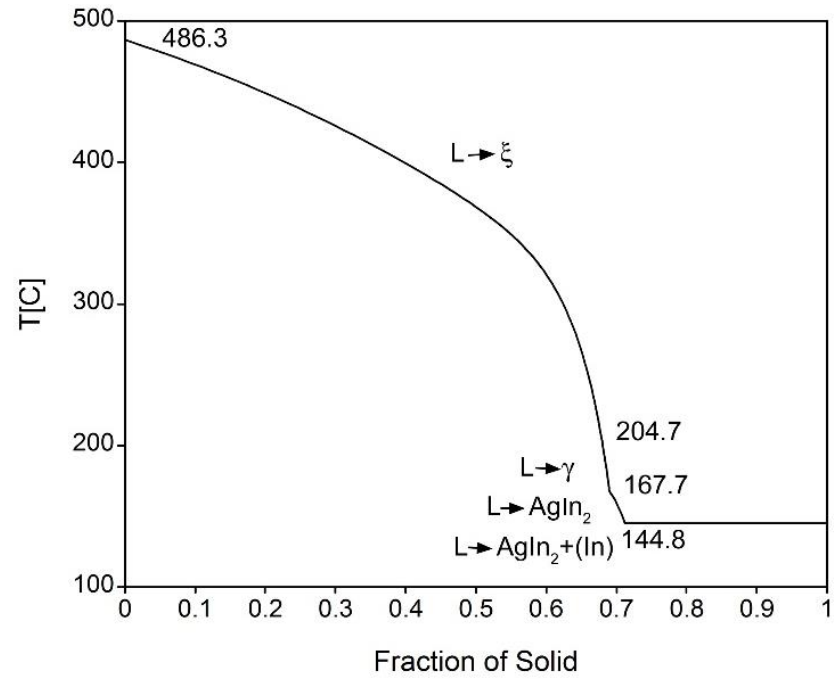

(b) 


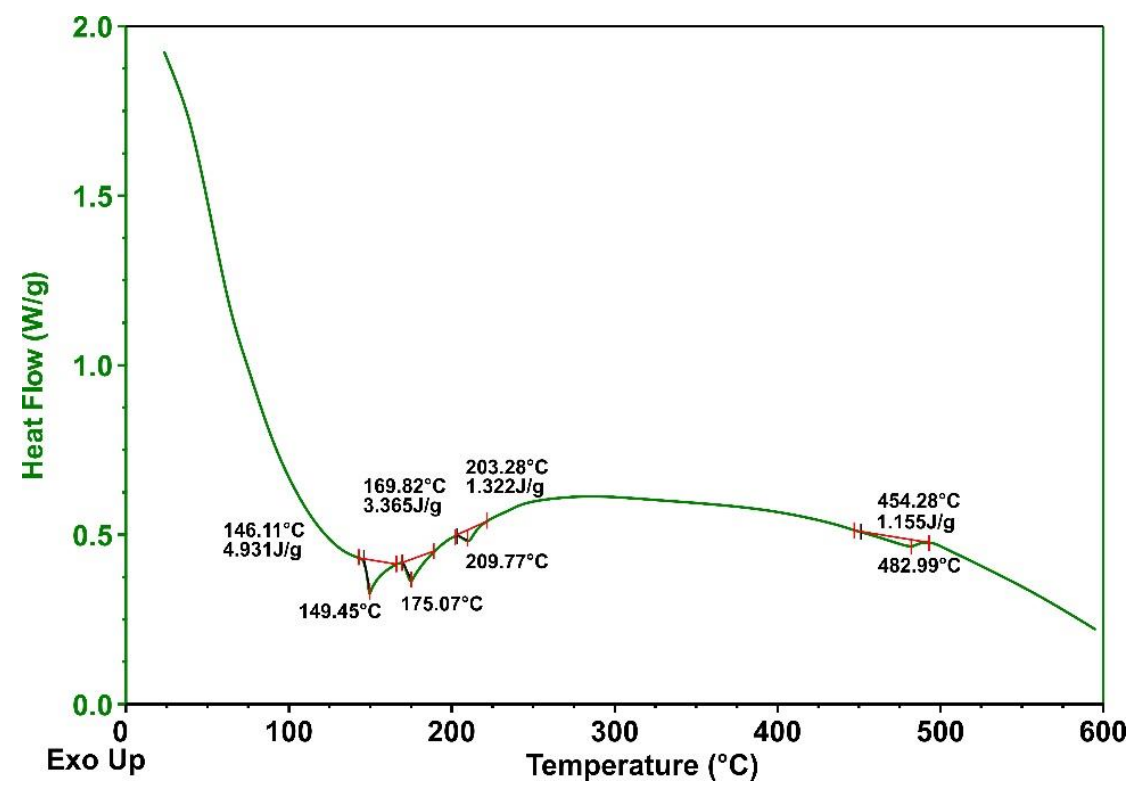

(c)

Fig. 4. In-45\%Ag alloy: (a) Equilibrium solidification path; (b) Non-equilibrium (Scheil) solidification path; (c) DSC heating curve.

According to the equilibrium solidification path (Fig. 4a), solidification of the alloy starts at $486.3^{\circ} \mathrm{C}$ (liquidus temperature) with the crystalization of primary $\xi$ phase. With further cooling, the phase fraction of the $\xi$ phase increases and the phase fraction of the liquid phase at the same time deacreses. At $204.7^{\circ} \mathrm{C}$ metatectic reaction appears, which causes decomposition of all $\xi$ phase into the $\gamma$ and liquid phases according to the $\xi \rightarrow \gamma$ +liquid reaction. Further cooling causes additional formation of $\gamma$ phase from the liquid. Solidification of the alloy finishes at $167.7{ }^{\circ} \mathrm{C}$, with appearance of $\gamma+$ liquid $\rightarrow \mathrm{AgIn}_{2}$ peritectic reaction. Metatectic and peritectic reactions are represented with the corresponding horizontal lines at the calculated solidification path curve. At room temperature microstructure of the alloy includes $\gamma$ phase (40\% phase fraction) and $\mathrm{AgIn} 2$ phase (60\% phase fraction).

As can be noticed from the calculated non-equilibrium (Scheil) solidification path, the assumption of no solid diffusion in the Scheil model completely prevents the occurrences of metatectic and peritectic reactions at 204.7 and $167.7^{\circ} \mathrm{C}$. When crossing the metatecic and peritectic temperatures during solidification, the freezing process merely switches from $\mathrm{L} \rightarrow \xi$ to $\mathrm{L} \rightarrow \gamma$ and further to $\mathrm{L} \rightarrow \mathrm{AgIn}_{2}$. Solidification of the alloy is not terminated at the peritectic temperature $167.7{ }^{\circ} \mathrm{C}$, as in the case of equilibrium conditions. It continues with the crystallization of $\mathrm{AgIn}_{2}$ from the melt and is finally finished with the occurrence of $\mathrm{L} \rightarrow \mathrm{AgIn}_{2}+(\mathrm{In})$ eutectic reaction at $144.8^{\circ} \mathrm{C}$. It can be seen that experimental DSC heating curve represents intermediate to these two extreme solidification models. It includes DSC peak related to the eutectic reaction predicted by the Scheil non-equlibrium solidification model but also includes DSC peaks related to the peritectic and metatectic reaction that correspond to the equilibrium conditions. 


\section{Investigation of thermal conductivity}

Thermal conductivity is important thermal property involved in development and application of various simulation models such as casting and soldering.

Thermal conductivity of the In-Ag alloys is not fully known yet. The values of thermal conductivity for pure constitutive metals In and $\mathrm{Ag}$ can be found in reference literature [10]. Silver has the highest thermal conductivity of all metals $\left(428.0 \mathrm{Wm}^{-1} \mathrm{~K}^{-1}\right.$ at $20^{\circ} \mathrm{C}$ ). Indium has moderately high thermal conductivity $\left(83.7 \mathrm{Wm}^{-1} \mathrm{~K}^{-1}\right.$ at $\left.20{ }^{\circ} \mathrm{C}\right)$. Thermophysical properties of pure metals Ag and In are given in Table 1.

Table 1. Thermophysical properties of pure metals Ag and In [1].

\begin{tabular}{lccccc}
\hline Metal & $\begin{array}{c}\text { Melting } \\
\text { point }\left({ }^{\circ} \mathrm{C}\right)\end{array}$ & $\begin{array}{c}\text { Latent heat of } \\
\text { fusion }\left(\mathrm{Jg}^{-1}\right)\end{array}$ & $\begin{array}{c}\text { Density } \\
\left(\mathrm{gcm}^{-3}\right)\end{array}$ & $\begin{array}{c}\text { Specific heat } \\
\text { capacity } \\
\left(\mathrm{Jg}^{-1} \mathrm{~K}^{-1}\right)\end{array}$ & $\begin{array}{c}\text { Thermal } \\
\text { conductivity } \\
\left(\mathrm{Wm}^{-1} \mathrm{~K}^{-1}\right)\end{array}$ \\
\hline $\mathrm{Ag}$ & 961.9 & 104.2 & 10.49 at $20^{\circ} \mathrm{C}$ & $\begin{array}{c}0.235 \text { at } 25^{\circ} \mathrm{C} \\
0.239 \text { at } 127^{\circ} \mathrm{C}\end{array}$ & 428 at $20^{\circ} \mathrm{C}$ \\
In & 156.61 & 28.47 & 7.30 at $20^{\circ} \mathrm{C}$ & 0.233 at $25^{\circ} \mathrm{C}$ & 83.7 at $20^{\circ} \mathrm{C}$
\end{tabular}

In this study, the thermal conductivity of solid In-Ag alloys has been determined within the temperature range from 25 to $100{ }^{\circ} \mathrm{C}$ using the flash method. The flash technique directly measures thermal diffusivity. It can also be used for the measurement of specific heat capacity although the uncertainty of the measured values is usually high [11].

Xenon lump (xenon-flash method) as a heat source supplies energy pulse to the front face of a thin disk specimen, and the temperature as a function of time at the rear face is automatically recorded. Determination of thermal diffusivity is based on following equation proposed by Parker et al. [12]:

$$
\alpha=\frac{1.37 L^{2}}{\pi^{2} t_{1 / 2}}=0.1388 \frac{L^{2}}{t_{1 / 2}}
$$

where $L$ represents the thickness of the sample and $t_{1 / 2}$ is the half-rise time, defined as time interval required for the back-face temperature to reach half of the maximal temperature value.

Thermal conductivity of the investigated samples was determined using the following relation:

$$
\lambda=\alpha \cdot \rho \cdot C p
$$

where $\lambda$ is thermal conductivity $\left(\mathrm{Wm}^{-1} \mathrm{~K}^{-1}\right), \alpha$ is thermal diffusivity $\left(\mathrm{m}^{2} \mathrm{~s}^{-1}\right), \rho$ is density $\left(\mathrm{kgm}^{-3}\right)$, and $\mathrm{Cp}$ is specific heat capacity $\left(\mathrm{Jg}^{-1} \mathrm{~K}^{-1}\right)$. The density values of the alloys at room temperature were derived from the measured mass and determined volume of the samples. They were assumed to be constant for calculation of thermal conductivity within the temperature interval $25-100{ }^{\circ} \mathrm{C}$. Taking into account rather small investigated temperature range, it can be assumed that this approximation does not have a significant effect on the calculated values of thermal conductivity. Specific heat capacities of the 
studied alloys in the temperature range from 25 to $100{ }^{\circ} \mathrm{C}$ were calculated using the thermodynamic database [4].

The obtained values of thermal diffusivity, specific heat capacity, and thermal conductivity for the In-Ag alloys investigated in the temperature range from 25 to $100^{\circ} \mathrm{C}$ are given in Table 2 . The standard uncertainty ( 0.68 level of confidence) for the thermal diffusivity measurements is $\pm 2 \%$ [13]. The total standard uncertainty $(0.68$ level of confidence) for the thermal conductivity is estimated to be $\pm 8 \%$ [13].

Table 2. Specific heat capacity, density, thermal diffusivity, and thermal conductivity of the investigated In-Ag eutectic alloys obtained in the present study.

\begin{tabular}{lcccc}
\hline $\begin{array}{l}\text { Alloy } \\
(\text { wt.\%) }\end{array}$ & $\begin{array}{c}\text { Temperature, } \\
\left({ }^{\circ} \mathrm{C}\right)\end{array}$ & $\begin{array}{c}\text { Calculated } \\
\text { specific heat } \\
\text { capacity, } \\
\mathrm{Cp}\left(\mathrm{Jg}^{-1} \mathrm{~K}^{-1}\right)\end{array}$ & $\begin{array}{c}\text { Thermal } \\
\text { diffusivity, } \\
\alpha\left(\mathrm{mm}^{2} \mathrm{~s}^{-1}\right)\end{array}$ & $\begin{array}{c}\text { Thermal conductivity } \\
\lambda\left(\mathrm{Wm}^{-1} \mathrm{~K}^{-1}\right)\end{array}$ \\
\hline \multirow{3}{*}{ In95Ag5 } & 25 & 0.242 & 44.68 & $78.73 \pm 6.30$ \\
& 50 & 0.251 & 42.69 & $78.02 \pm 6.24$ \\
& 100 & 0.259 & 39.56 & $74.60 \pm 5.97$ \\
In85Ag15 & 25 & 0.245 & 41.49 & $77.19 \pm 6.18$ \\
& 50 & 0.248 & 41.21 & $77.61 \pm 6.21$ \\
& 100 & 0.255 & 38.69 & $74.92 \pm 5.99$ \\
In55Ag45 & 25 & 0.236 & 29.32 & $57.69 \pm 4.62$ \\
& 50 & 0.238 & 28.95 & $57.45 \pm 4.60$ \\
& 100 & 0.243 & 27.29 & $55.29 \pm 4.42$ \\
\hline
\end{tabular}

From Table 2 it can be seen that, for all three investigated alloys, specific heat capacity increases with increasing temperature. Calculated specific heat capacity values are in fair agreement with the experimentally determined values obtained by using the xenon-flash method. For example, for the In-15\% Ag alloy calculated value of specific heat capacity at $25{ }^{\circ} \mathrm{C}$ is $0.245 \mathrm{Jg}^{-1} \mathrm{~K}^{-1}$ (Table 3) and related measured value is $0.245 \mathrm{Jg}^{-}$ ${ }^{1} \mathrm{~K}^{-1}$. Thus, it can be concluded that specific heat capacities calculated by using the thermodynamic database are highly accurate. Specific heat capacities of In-Ag alloys are very close to the specific heat capacities of $\mathrm{Sn}-\mathrm{Ag}-\mathrm{Cu}$ solders [14]. Higher $\mathrm{Cp}$ means that more energy will be needed to raise the temperature of the solder.

The values of thermal conductivity of In-5\% Ag and In-15\% Ag alloys are very close to each other and slightly lower than the thermal conductivity of pure In $\left(83.7 \mathrm{Wm}^{-}\right.$ ${ }^{1} \mathrm{~K}^{-1}$ at $20^{\circ} \mathrm{C}$ ) while In-45\% Ag alloy possesses significantly lower thermal conductivity than previous two (Fig. 5). Thermal conductivity of the In-5\% Ag at $100{ }^{\circ} \mathrm{C}$ $\left(74.60 \pm 5.97 \mathrm{Wm}^{-1} \mathrm{~K}^{-1}\right)$ is in a close agreement with the published value of thermal conductivity for the In-3\% Ag solder alloy at $85{ }^{\circ} \mathrm{C}\left(73.0 \mathrm{Wm}^{-1} \mathrm{~K}^{-1}\right)$. It is important to note that the addition of $\mathrm{Ag}$ does not cause an increase in alloy thermal conductivity. In contrast, there is a decrease in thermal conductivity, which is especially noticeable for the In-45\% Ag alloy. This finding is in agreement with the results of Kondo et al. [5] for the liquid In-Ag alloys and published thermal conductivity data for the In-3\% Ag and In-10\% $\mathrm{Ag}$ at $85^{\circ} \mathrm{C}$ [1]. It is known that the thermal conductivity of intermetallic phases is much lower than the thermal conductivity of the constitutive metals [15]. Thus, it can be 
concluded that the thermal conductivity of In-Ag alloys decreases with increasing the amounts of $\mathrm{AgIn}_{2}$ and $\mu$ phases.

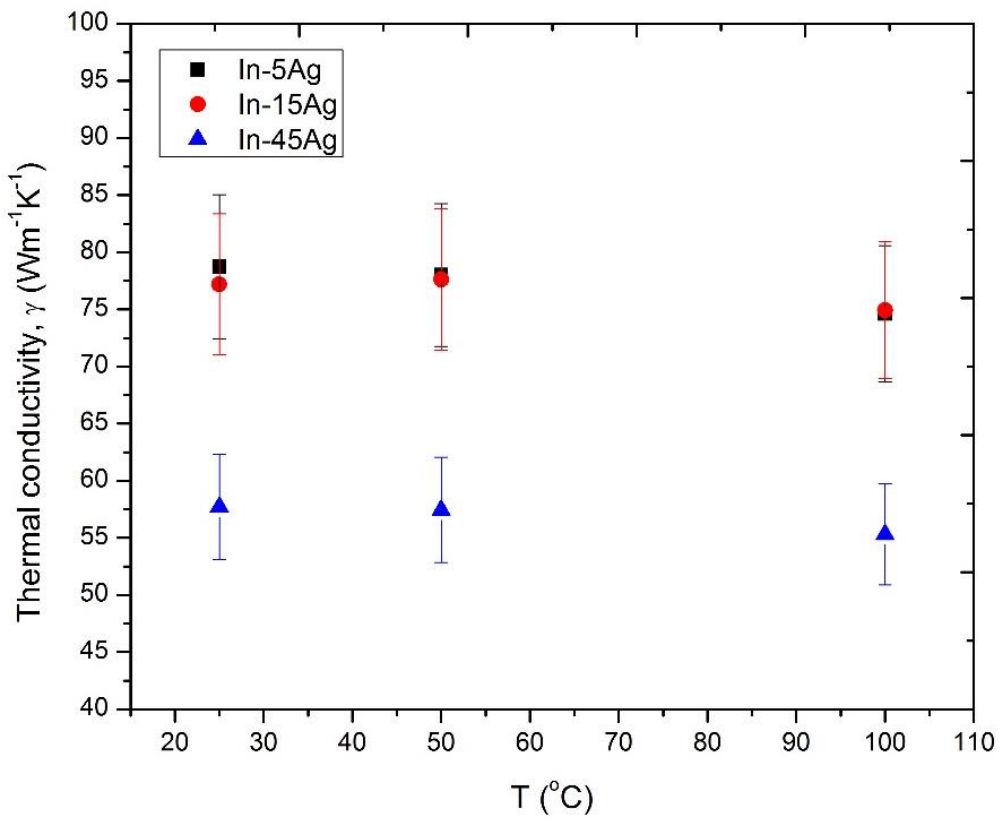

Fig. 5. Thermal conductivity of investigated In-Ag alloys as a function of temperature and composition.

\section{Conclusions}

In the present study phase transformations and melting behavior of the In-Ag alloys were investigated using the DSC method. The interpretation and analysis of DSC heating scans were performed with the assistance of equilibrium and non-equilibrium solidification paths computed from thermodynamic data. Due to the complexity of the InAg phase diagram and the occurrence of metatectic and peritectic solid-state diffusion reactions, calculated equilibrium and non-equilibrium Scheil solidification paths considerably differ from each other for all three investigated alloy compositions. Experimental DSC results are in general agreement with the calculated phase transition temperatures although some additional peaks predicted by Scheil model appear also. This indicates that fully equilibrium conditions were not reached during DSC measurements. Thermal conductivity for the three investigated alloys was determined in the temperature range from 25 to $100{ }^{\circ} \mathrm{C}$. Thermal conductivities of the investigated alloys are less than the thermal conductivity of pure In and gradually decrease with increasing temperature and $\mathrm{Ag}$ content.

\section{Acknowledgments}

The research presented in this paper was done with the financial support of the Ministry of Education, Science and Technological Development of the Republic of 
Serbia, within the funding of the scientific research work at the University of Belgrade, Technical Faculty in Bor, according to the contract with registration number 451-0368/2020-14/ 200131.

\section{References}

[1] ASM Handbook Volume 2: Properties and Selection: Nonferrous Alloys and Special-Purpose Materials, Materials Park, OH, ASM International, 1990.

[2] A. Reti: Silver: Alloying, Properties, and Applications. In: Encyclopedia of Materials: Science and Technology, Elsevier, 2001. pp. 8618-8621.

[3] Z. Moser, W. Gasior, J. Pstrus, W. Zakulski, I. Ohnuma, X. J. Liu, Y. Inohana \& K. Ishida: J Electron Mater, 30 (2001) 1120-1128.

[4] A. Kroupa, A.T. Dinsdale, A. Watson, J. Vrestal, J. Vízdal, A. Zemanova: JOM, 59 (2007) 20-25.

[5] T. Kondo, Y. Ohishi, H. Muta, K. Kurosaki, S. Yamanaka: J Nucl Sci Technol, 55 (5) (2018) 568-574.

[6] D. Manasijević, Lj. Balanović, V. Ćosović, D. Minić, M. Premović, M. Gorgievski, U. Stamenković, N. Talijan: Metall Mater Eng, 25 (4) (2019) 325334.

[7] W. Cao, S.L. Chen, F. Zhang K. Wu, Y. Yang, Y. A. Chang, R. Schmid-Fetzer, W. A. Oates: Calphad, 33 (2009) 328-342.

[8] W.J. Boettinger, U.R. Kattner, K.W. Moon, J.H. Perepezko: DTA and Heat-flux DSC Measurements of Alloy Melting and Freezing. In: J.C. Zhao, ed. Methods for Phase Diagram Determination. Amsterdam: Elsevier Science; 2007, 151-221.

[9] M.C. Flemings: Solidification Processing, McGraw Hill, NY, 1974, p. 177.

[10] Y.S. Touloukian, R.W. Powell, C.Y. Ho, P.G. Klemens: Thermal Conductivity of Metallic Elements and Alloys. Vol. 1. Washington, New York 1970.

[11] M. Kövér, M. Behúlová, M. Drienovský, P. Motyčka: J Therm Anal Calorim, 122 (2015) 151-156.

[12] W.J. Parker, R.J. Jenkins, C.P. Butler, G.L. Abbott: J Appl Phys, 32 (1961) 16791684.

[13] L. Huang, S. Liu, Y. Du, C. Zhang: Calphad, 62 (2018) 99-108.

[14] J.K. Wu, K.L. Lin, B. Salam: J Electron Mater, 38 (2009) 227-230.

[15] Y. Ocak, S. Aksöz, N. Maraşlı, K. Keşlioğlu: J Non-Cryst Solids, 356 (2010) 1795-1801.

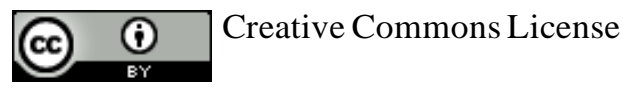

This work is licensed under a Creative Commons Attribution 4.0 International License. 